\title{
Essentialism and Folkbiology: Evidence from Brazil ${ }^{*}$
}

\section{Paulo Sousa, ScotT Atran and Douglas Medin}

\begin{abstract}
Experimental results in reference to Brazilian children and adults are presented in the context of current discussions about essentialism and folkbiology. Using an adoption paradigm, we replicate the basic findings of a previous article in this journal concerning the early emergence in children of a birth-parent bias (Atran et al. 2001). This cognitive bias supports the claim that causal essentialism cross-culturally constrains the reasoning about the origin, development and maintenance of the characteristics and identity of living kinds. We also report some intriguing differences with earlier findings that speak to theoretical and methodological issues of cultural relativity.
\end{abstract}

KEYWORDS

Adoption paradigm, Essentialism, Folkbiology.

\section{Introduction}

There are two competing accounts of how human beings acquire basic knowledge of the ordinary biological world, including the categorial limits of its domain and the causal structure of its fundamental constituents. According to one view, by ages 4 and 5, children have already acquired systematic folkbiological knowledge, which may be the result of an innate propensity to conceptualize living kinds in specific ways (see Atran et al. 2001; Atran 1987, 1990; Keil 1989; Gelman \& Wellman 1991; Hatano \& Inagaki 1994; Springer 1995, 1996). The alternative view contends that only after age 7 do children start to elaborate a folk framework with a specific conception of biological causality (see Carey 1985, 1995; Carey \&

*We wish to thank Michael Baran, Guy Politzer and Dan Sperber for comments on earlier drafts, or on specific points of the article. E-mail for correspondence: psousa@umich.edu 
Spelke 1994; Johnson \& Solomon 1997; Johnson \& Carey 1998, Solomon et al. 1996).

The adoption paradigm has been one of the main sources of evidence in the debate between these two opposing views (see, e.g., Astuti 2001, Atran et al. 2001, Block et al. 2001, Solomon et al. 1996; Johnson \& Solomon 1997, Springer 1996). This experimental task is a story about a baby reared exclusively by adoptive parents - i.e., without ever having any contact with its birth parents after the adoption - , and an inquiry whether the grow-up baby would resemble its birth parents or its adoptive parents. For example, one tells a story about a cow's baby that was adopted by pigs just after birth, and that grew up with pigs, without ever seeing a cow again. Then, one asks if the grown-up baby resembles a cow or a pig. ${ }^{1}$ Two general types of resemblance are at stake here: property similarity and kind similarity. For example, one asks if the grown-up baby moos like a cow or oinks like a pig, and asks if it is a cow or a pig. Therefore, the inquiry is whether the grown-up baby has the properties and the identity of its birth parents or of its adoptive parents. Participants in this task normally range from 4 year olds to adults, and the experimental aim is to ascertain how they project properties and categorize the grown-up baby.

The two possible answers are normally described by a general opposition between nature (resemblance to the birth parent) and nurture (resemblance to the adoptive parent). It is as if, guiding each type of answer, there were respectively a conception of nature and a conception of interaction with the environment as the main causal mechanisms responsible for the acquisition of properties and identity, however vague these mechanisms. Nevertheless, it is important to have in mind that this "theory-laden"2 description should not exclude the possibility that what is guiding a specific type of answer is a conception of a mixed mechanism. Consider:

\footnotetext{
${ }^{1}$ There are two general forms of the adoption paradigm: one in which the adoption is across families, and one in which the adoption is across species. Our primary focus in this article is on the cross-species form.

${ }^{2}$ In this article, we use double quotation marks as scare quotes or for quotation, single quotation marks for mention, and italics for meaning or emphasis.
} 
Malagasy will often tell you such things as that (...) their children have whiter skin because they spent a lot of time associating with a French missionary. (Bloch et al. 2001: 48)

(...) there is evidence that the Dutch colonial administration in the 19thcentury was convinced (or worried) that too long an exposure to Javanese culture and climate would cause Dutch settlers to become Javanese in some sense (Stoler 1995). (Gelman \& Hirschfeld 1999: 437)

If it is plausible to suppose that what is implied in these passages is an idea akin to natural contagion (Gelman and Hirschfeld 1999: 437; Weissman \& Kalish 1999: 246), it is possible to hypothesize that adoptiveparent answers in the adoption task are driven by a similar conception a causal mechanism that mixes nature and nurture. ${ }^{3}$ Also, this "theoryladen" description should not imply that what guides any of the answers is always a conception of a causal mechanism responsible for the acquisition of properties and identity. The range of plausible explanations is not restricted to such a conception, as will become apparent later.

Critical to the debate between the two opposing views as regards the timetable of the acquisition of folkbiological knowledge is the evidential status of the birth-parent type of answer. This is because they disagree about whether a significant pattern of birth-parent answers by young children can be considered evidence for the hypothesis that they possess folkbiological knowledge. Those who sustain the "by-ages-4-and-5" view tend to accept that such a pattern of response can be evidence. The alternative "after-age-7" view has a double doubt about this possibility: the first, more reactive, points out that other hypotheses could account for young children's birth-parent pattern of performance; the second, more radical, advocates that to take this pattern as an evidential criterion is misleading, and proposes another one - the property-differentiation criterion.

In the next section, we offer a rational reconstruction, in the philosophical sense, of the hypotheses suggested by the current literature that could

\footnotetext{
${ }^{3}$ Throughout the article, we will refer to the two possible answers by the expressions 'adoptive-parent answer,' when participants indicate that the grown-up baby resembles the adoptive parents, and 'birth-parent answer,' when participants indicate that the grown-up baby resembles the birth parents.
} 
explain a birth-parent type of answer. Then, we describe the version of the adoption paradigm we applied in Brazil, and analyze the results. Finally, we discuss the hypotheses in light of the Brazilian data, and argue that the results give some support to the view that by ages 4 and 5 Brazilian children possess relevant folkbiological knowledge. We also show a fundamental incommensurability between the property-differentiation criterion proposed by the alternative view, and what can count as evidence from our perspective.

\section{Hypotheses}

Suppose we apply a version of the adoption task mentioned in the introduction. We tell a story about a cow's baby that was adopted by pigs just after birth without ever seeing a cow again. We then ask the questions about the grown-up baby. Now, suppose participants indicate birth-parent answers - "it moos" and "it is a cow." If participants pay attention to the story, understand it, and do not guess, they probably base their replies on certain assumptions and inferences. Our aim in this section is to characterize some general hypotheses concerning the basic assumptions and inferences that participants entertain when they indicate a birth-parent type of response. The current literature suggests three hypotheses in this regard.

In all three hypotheses, participants' inferences are based on three schematic assumptions: ${ }^{4}(\mathrm{P} 1)$ the lineage assumption (the baby has the same kind identity of the $X$ that gave birth to it); (P2) the permanence assumption (the grown-up baby will have the same kind identity $X$ of the baby); (P3) the property assumption ( $X$ has characteristic $A$ ). Accordingly, participants would have computed the following inferences to respond to the task probes:

(P1) The baby of a cow is a cow.

(P2) The baby cow will be a grown-up cow.

(P3) Cows moo.

(C1) The grown-up baby is a cow (from P1 \& P2).

(C2) The grown-up baby moos (from C1 \& P3).

\footnotetext{
${ }^{4}$ These schematic assumptions should be considered as logical forms with a strict logicsemantic content, as characterized by Sperber \& Wilson 1995: chapter 2.
} 
Assuming premises $(\mathrm{P} 1)$ and $(\mathrm{P} 2)$, participants can infer $(\mathrm{C} 1)$. For example, if, instead of (P2), they assume that the baby cow will become an adult pig (or, as for that, any adult kind other than a cow), they would not infer (C1). Assuming (C1) and (P3), they can infer $(\mathrm{C} 2) .{ }^{5}$ If participants in the adoption task make similar inferences, we can explain why they indicate the birth-parent answers.

Each of the three hypotheses is a specific interpretation of the schematic assumptions just described. The first can be named 'the correlational hypothesis.' It is suggested in the following passages:

(...) preschoolers might know the fact that dogs give birth to dogs and cats give birth to cats before they have embedded this knowledge into an explanatory relation such that they understand that a dog is a dog, because a $\operatorname{dog}$ (or, if and only if) a dog gave birth to it. (Johnson \& Solomon 1997: 405)

As of now, there is no evidence that pre-school children have a concept of biological inheritance that goes beyond expectations of resemblance between parents and their offspring, i.e. they do not distinguish between different kinds of mechanisms by which such resemblance comes into being. Thus, just as in their case of their knowledge of growth, pre-school children's knowledge of family resemblance appears to be an explained fact about animals that they have acquired, presumably through domain-general learning mechanisms. (Carey 1995: 290) $)^{6}$

According to this hypothesis, the reasoning behind the birth-parent answers is based on three empirical correlations: (1) There is a correlation between the kind identity of a baby and the identity of the kind $X$ that gave birth to it; (2) There is a correlation between the kind identity of a grown-up and its kind identity $X$

${ }^{5}$ Even though, in these strict deductive inferences, the assumption that the baby cow becomes an adult cow with the characteristics of the cow species is not necessary, in the following inferences, this will be either a default assumption or something implied by specific conceptions. Our aim in this section is not to give a complete account of the assumptions and inferences involved in the task, but simply to be more explicit than the current literature.

${ }^{6}$ It is interesting to notice that a similar family resemblance version has been proposed to explain the adoptive-parent type of answer as well: "the [adoptive] pattern could simply reflect the two-step reasoning that a boy will resemble his parents and that the relevant parents are those who bring the child up" (Block et al. 2001: 59). Our characterization will be an attempt to explicate the specificity of the birth-parent case. 
when it was a baby; (3) There is a correlation between being an $X$ and having characteristic $A$. Therefore, the following type of reasoning would be the basis for participants' responses to the task probes: ${ }^{7}$

(P1) The baby's cow identity is correlated with the identity of the cow that gave birth to it.

(P2) The grown-up's cow identity is correlated with its identity when it was a baby cow.

(P3) Being a cow is correlated to mooing.

(C1) The grown-up baby is a cow (from P1 \& P2).

(C2) The grown-up baby moos (from C1 \& P3).

Two points need emphasis. First, the hypothesized reasoning involves an understanding of regularity without any causal understanding. At stake here is a psychological version of David Hume's interpretation of regularity, or, to put it in terms of statistics, a regularity that is used to predict but not to explain. ${ }^{8}$ For example, one may notice that every afternoon, when the Church bell rings, the next-door neighbor leaves her house, and may assume that there is a regular connection between these two events. Then, one can predict when the next-door neighbor leaves her house, without supposing that the sound of the bell causes her leaving her house. Second, according to this hypothesis, there is no conception of a natural mechanism involved in this reasoning, since the correlations are formed by domain general mechanisms that trace empirical regularities and do not imply any specific understanding of its domain of reference.

${ }^{7}$ Notice that in exemplifying the reasoning involved in the schematic assumptions, oftentimes we will be condensing inferences into the premises - e.g., (P1): a baby's identity is correlated to the identity of the kind $X$ that gave birth to it; the baby's identity is correlated to the identity of the cow that gave birth to it; therefore, the baby is a cow.

${ }^{8}$ The opposition between correlation/prediction and explanation that we find in statistics — the latter implying causation, the former not —, is not embraced by the Humean tradition in philosophy of science that eliminates the notion of causation by reducing the notion of explanation to a type of argument (see Salmon et al. 1992). It is also important to notice that what is relevant in characterizing the correlational hypothesis is the absence or presence of causal understanding, not the universal or probabilistic status of the regularities. Consequently, this reasoning can be either a deduction or an induction, depending on how participants interpret the scope of the correlations. 
The second interpretation of the schematic assumptions can be named 'the natural kind hypothesis.' It has been advanced by Strevens in his minimalist interpretation of essentialism:

(...) essentialist hypotheses have their explanatory power because they attribute to the child belief in certain causal laws, namely, causal laws connecting kind membership with observable properties. An example is the law that tigers have stripes. I emphasize that this is to be understood as a causal law. It is not just that, statistically, tigers tend to have stripes. Rather, there is something about being a tiger that causes tigers to have stripes. I take this formulation to be equivalent to it is a causal law that tigers have stripes. (Strevens 2000: 104)

According to this hypothesis, the reasoning behind the birth-parent answers is based on three natural kind laws: (1) the natural kind identity of a baby is caused by the fact that a natural kind $X$ gave birth to it; (2) a natural kind $X$ grows to be an adult $X$; (3) being a natural kind $X$ causes $X$ to have characteristic $A .{ }^{9}$ Therefore, the following type of reasoning would be the basis for participants' responses to the task probes:

(P1) The baby is a cow because a cow gave birth to it.

(P2) The baby cow grows to be an adult cow.

(P3) Being a cow causes a cow to moo.

(C1) The grown-up baby is a cow (from P1 \& P2).

(C2) The grown-up baby moos (from C1 \& P3).

Two points need emphasis. First, the hypothesized reasoning does involve causal understanding, albeit shallow and atheoretical one. ${ }^{10}$ At stake here is a causal understanding of empirical regularities without any theoretical understanding of why the causal regularities hold. For example, one may observe that a bar of iron always expands when heated, and interpret this regularity as a causal law in the service of explanation: a (token) bar of iron expanded because it was heated. In this case, however, one does not use any theoretical knowledge about the

${ }^{9}$ For the sake of uniformity, we don't abide by all details of Strevens' position. For example, he would interpret the lineage assumption as an indefeasible biconditional law, not a defeasible causal law.

${ }^{10}$ For an interesting discussion of this distinction between shallow and theoretical causation in the context of the philosophy of science, see McMullin 1978. 
molecular structure of the iron to understand why the bar expands when heated. Second, according this hypothesis, even if there is no theoretical understanding of the metaphysical underpinnings of causation, there is a minimal understanding of what makes the causal law a natural kind law. Therefore, there is a minimal assumption about the specificity of the domain of natural kinds.

The third interpretation of the schematic assumptions can be named 'the causal essentialism hypothesis' (see Ahn et al. 2001; Atran 1987, 1990; Gelman \& Hirschfeld 1999; Kalish 1995; Medin 1989; Medin \& Ortony 1989). This is our favored hypothesis. According to it, the reasoning behind the birth-parent answers is based on assumptions about essences: (1) the natural kind identity of a baby is caused by the fact that a natural kind $X$ gave birth to $i$, because the baby inherits $X$ 's essence; (2) a natural kind $X$ grows to be an adult $X$, because its essence gives the innate potential to be so; (3) in normal circumstances, the essence of natural kind $X$ causes $X$ to have characteristic $A$. Therefore, the following type of reasoning would be the basis for participants' responses to the task probes:

(P1) The baby of the cow is a cow, because the cow's essence is inherited.

(P2) The baby cow grows to be an adult cow, because of its innate potential.

(P3) In normal circumstances, the essence of a cow causes a cow to moo.

(C1) The grown-up baby is a cow (from P1 \& P2).

(C2) The grown-up baby moos (from G1 \& P3).

Two points need emphasis. First, the hypothesized reasoning does involve a theoretical, even if intuitive, understanding: the notion of essence explains why the causal relations hold. This notion is typically conceived without being defined, but implies certain characteristics. The essence exists. It can be ontologically indeterminate in regard to its basic ontological mode, although it is normally interpreted as having a non-transient mode of existence (e.g., as a substance, quality, structure, or object, but not as an event). It can be indeterminate in terms of its location, although it is normally interpreted as localized inside each individual of a kind; it can even be identified with a known fixed internal part of the individuals of a kind (e.g., the heart, the blood, or the DNA). It is typically non-observable. It is transferable, typically by birth, without loosing its causal powers. It has a special type of causal power, one that, in normal circumstances, 
causes the individuals of a kind to develop and maintain the characteristic properties of the kind. Its possession is a necessary and sufficient condition for kind identity, but does not preclude the conception of blended kinds (e.g., a mule as a hybrid of a horse and a donkey). Second, according to this hypothesis, this notion of essence constitutes some of the basic biological intuitions - intuitions about internal structure, inheritance, biological relatedness, innate potential, and the development and maintenance of characteristics and identity. ${ }^{11}$

\section{Method}

So far we have discussed a general version of the adoption paradigm, one that highlights the structural features that are relevant to characterize the assumptions and inferences involved in a birth-parent type of response. In this section, we present the specific version we ran in Brazil.

\section{Participants}

Participants were 120 Brazilian middle class children and adults from two different Brazilian urban cities - Belo Horizonte, the capital of the state of Minas Gerais, and Brasilia-DF, the capital of Brazil. Twenty-four 4 year

\footnotetext{
${ }^{11}$ Another suggestion from the literature could perhaps constitute an additional hypothesis to explain birth-parent answers. Susan Carey has invoked the following notion of linguistic essentialism to explain the results of a task whose design is in a way similar to an adoption paradigm (cf. Gelman and Wellman 1991): "Essentialism, like taxonomic structure, derives from the logical work done by nouns. The child has a default assumption that count nouns are substance sortals, i.e. naming concepts that provide conditions of identity during the maximal lifetime of an entity (...) the application of every count noun carries with it the idea that the identity of the entity picked out by the noun is unchanged in the face of surface changes" (Carey 1995: 277). This notion is a kind of permanence assumption $[(\mathrm{P} 2)$ the identity of the reference a count noun ' $X$ ' ('cow') is maintained over time] with a sortal role that differs from the sortal roles of both classical and causal essentialisms: it does not imply definitions in the classical sense, nor does it imply causality in the sense of causal essentialism. This permanence assumption could constitute another explanation of birth-parent answers if added to two other ones: a reference assumption $[(\mathrm{P} 1)$ a count noun ' $X$ ' ('cow') refers to a $X$ (cow)] and a property assumption [(P3) kind $X$ (cows) has characteristic $A$ (moo)]. But, in this case, because the birth-parent conclusions (C1) [from (P1) \& (P2)] and (C2) [from (C1) \& (P3)] can only be inferred if the baby of the story is called a 'baby cow' - what is never the case in the adoption paradigm — , it seems to us that the notion of linguistic essentialism cannot constitute a possible explanation for birth-parent answers.
} 
olds $(\mathbf{M}=4 ; 8$, range $=4 ; 4-4 ; 11)$, twenty-four 5 year olds $(\mathbf{M}=5 ; 6$ years, range $=5 ; 1-5 ; 11)$, twenty-four 6 year olds $(\mathrm{M}=6 ; 6$ years, range $=$ $6 ; 1-6 ; 11)$, twenty-four 7 year olds $(M=7 ; 5$ years, range $=7 ; 0-7 ; 11)$ and twenty-four adults $(\mathrm{M}=31$ years; range $=14-56)$ were included in the analysis. Each age group comprised an equal number of females and males. Participants were tested in Brazilian Portuguese by a native speaker (one of the authors of the article). Children were tested individually in a separate classroom of their respective schools. ${ }^{12}$ Adults were tested individually in different settings.

\section{Procedure}

In a forced choice task, participants were asked whether an animal adopted at birth would resemble its birth parent or its adoptive parent when it is a grown-up. They were told the following story: ${ }^{13}$

One day a cow gave birth to a little baby. Here's a drawing of the cow that gave birth to the baby [participant sees the drawing of the cow - see Figure 1]. Right after the baby was born the cow died without ever seeing the baby [drawing of the cow is removed]. The baby was found and taken right away to live with pigs in a place where there are lots of pigs. Here's a drawing of the pig [participant sees the drawing of the pig - see Figure 1] that took care of the baby the whole time that the baby was growing up [drawing of pig is removed]. The baby grew up with pigs and never saw another cow again.

The story was followed by two comprehension controls: (i) a birth control: "who gave birth to the baby? Point out the drawing of who gave birth to the baby" [drawings of the two parent animals are shown], and (ii) a nurture control: "who did the baby grow up with? Point out the drawing of whom the baby grew up with" [drawings of the two parent animals are shown]. If a participant failed either or both control questions, the adoption story was repeated; in the case of a second failure, the participant was excluded from the experiment.

${ }^{12}$ To verify the translation to Portuguese and adjust the design, we ran a pilot with all children age groups. None of the participants in the pilot was included in this sample.

${ }^{13}$ The story was preceded by two warm-up questions: "A baby lion grew up with other lions in the forest. Now that the baby is all grown up does it drink water or coffee? Is it brown or green?" 

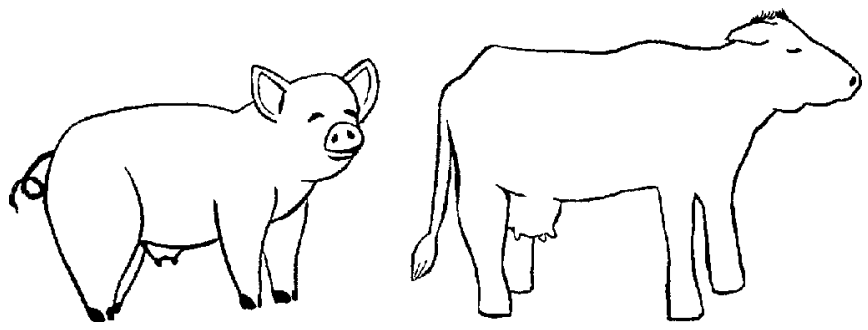

Figure 1. Examples of pictures of mother animals.

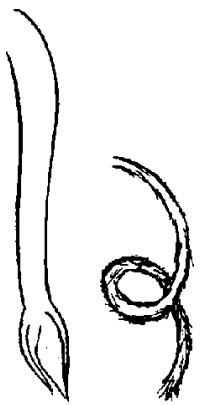

Figure 2. Examples of known properties (straight vs. curly tail).

Next, participants were presented with four property research probes. Two of them related to known properties: (i) known behavior: "The cow moos and the pig oinks. Now that the baby is all grown up, does it moo like a cow or oink like a pig?? [drawings of the two parent animals are shown]), and (ii) known physical trait: "the cow has a straight tail like this and the pig has a curly tail like this" [drawings of the traits are shown see Figure 2]. "Now that the baby is all grown up does it have a straight tail like a cow or a curly tail like a pig?" [drawings of the two parent animals are shown].

The other two property probes are related to unknown properties: (i) unknown behavior: "The cow runs after chickens and the pig runs after ducks. Now that the baby is all grown up does it run after chickens like a cow or after ducks like a pig?" [drawings of the two parent animals are shown], and (ii) unknown internal physical trait: "The cow's heart gets flatter when it sleeps and the pig's heart gets rounder when it sleeps" [drawings of the traits are shown - see Figure 3]. "Now that the baby is all grown up, when it sleeps does its heart get flatter like the one of the 

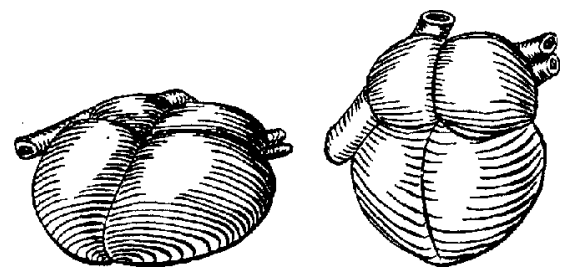

Figure 3. Examples of unknown properties (flat vs. round heart).

cow or get rounder like the one of the pig?" [drawings of the two parent animals are shown].

Known properties were category-typical characteristics that participants readily associated with the species, whereas unknown properties were chosen to minimize any possibility of pre-learned factual associations between the properties and the species. Three different sets of animal pairs with their respective known and unknown properties were used in the experiment (see appendix). The order of the presentation of the sets was randomized across participants, as was the order of the four property research probes. The order of presentation of parents within each probe was held constant for each participant and counterbalanced across participants. Each unknown property within a set was attributed to the birth parent for half of participants, and to the adoptive parent for the other half, in order to assure that projection patterns of the unknown properties were not based on prior knowledge.

The first four research probes were followed by a bias control probe: "When the baby was growing up did it play with animals that looked like a cow or animals that looked like a pig? Point out the animal that looks like the animals that the baby played with" [drawings of the two parent animals are shown]. This bias control probe was to check whether participants chose one answer initially — specifically the birth-parent one - , and repeated it subsequently via a route of least effort. If they answer the control question correctly - that the baby played with animals like the adoptive species —, we can reasonably suppose that they kept their attention on the story, understood the story, and that their previous answers weren't arbitrary. ${ }^{14}$

\footnotetext{
${ }^{14}$ Our control question here differs from the one in our original design, where the question was about which animals the baby ate with when it was growing up (Atran
} 
Next, participants were presented a fifth research probe about kindhood: "Now that the baby is all grown up, what kind of animal is it? Point out the kind of animal the baby grew up to be" [drawings of the two parent animals are shown].

In order to explore the extent to which species kindhood is associated with vital internal properties such as blood, a follow-up story was introduced:

When the baby was growing up it became sick. A doctor came and, with a needle, took out all of the old blood that the baby got from its mother [the drawing of the cow is shown] when it was born. The doctor then went to the animal that was taking care of the baby [the drawing of the pig is shown] and took some of its blood to give to the baby. So the baby got all new blood like the blood of the pig.

And a final blood probe, again about kindhood, was presented: "Now that the baby is all grown up, what kind of animal is it? Point out the kind of animal the baby grew up to be" [drawings of the two parent animals are shown].

\section{Results}

Participants made their choice by pointing to the relevant parent sketch. For each research probe, the answers were coded as ' 1 ' for birth-parent choice, and ' 0 ' for adoptive-parent choice. For the bias control probe, answers were coded as ' 1 ' if participants indicated that the baby played with animals like the birth parent, and ' 0 ' if they indicated that the baby played with animals like the adoptive parent. The proportions of birthparent answers in each of the probes (in order: known behavior, known physical trait, unknown behavior, unknown physical trait, kind, blood and control) are shown in graph 1 for each age group. Each proportion was tested against chance (0.5). Results appear in Table 1.

Overall, the results are significant either above or below chance. The very low proportions on the control probe for all age groups indicate that the design of the experiment did not bias the responses toward the birth

et al. 2001). When we tried this question in the pilot, Brazilian children kept choosing the birth-parent option, so we changed its content. We comment on this point in the final discussion. 


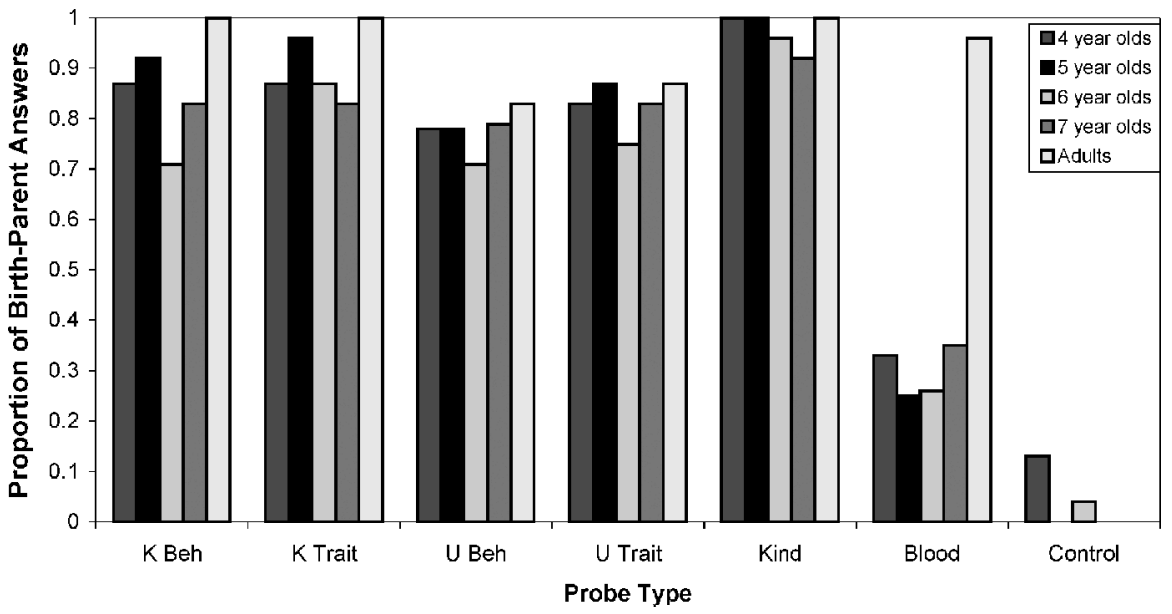

Graph 1. Adoption Paradigm.

Table 1

Proportions tested against chance

\begin{tabular}{rlllllll}
\hline & K BEH & K TRAIT & U BEH & U TRAIT & KIND & BLOOD & CONTROL \\
\hline $\begin{array}{r}4 \text { year } \\
\text { olds }\end{array}$ & $0.87^{* * *}$ & $0.87^{* * *}$ & $0.78^{* *}$ & $0.83^{* *}$ & $1.00^{* * *}$ & 0.33 & $0.13^{* * *}$ \\
$\begin{array}{r}5 \text { year } \\
\text { olds }\end{array}$ & $0.92^{* * *}$ & $0.96^{* * *}$ & $0.78^{* *}$ & $0.87^{* * *}$ & $1.00^{* * *}$ & $0.25^{*}$ & $0.00^{* * *}$ \\
$\begin{array}{r}6 \text { year } \\
\text { olds }\end{array}$ & $0.71^{*}$ & $0.87^{* * *}$ & $0.71^{*}$ & $0.75^{*}$ & $0.96^{* * *}$ & $0.26^{*}$ & $0.04^{* * *}$ \\
$7 \begin{array}{l}\text { year } \\
\text { olds }\end{array}$ & $0.83^{* *}$ & $0.83^{* *}$ & $0.79^{* *}$ & $0.83^{* *}$ & $0.92^{* * *}$ & 0.35 & $0.00^{* * *}$ \\
$\begin{array}{r}\text { Adults } \\
\hline\end{array}$ & $1.00^{* * *}$ & $1.00^{* * *}$ & $0.83^{* *}$ & $0.87^{* * *}$ & $1.00^{* * *}$ & $0.96^{* * *}$ & $0.00^{* * *}$ \\
\hline
\end{tabular}

$p<.05^{*}, p<.01^{* *}, p<.001^{* * *}$

parent choice. The performance of all age groups was above chance in every research probe except the blood probe. In the blood probe, adults performed above chance, and half of the children age groups performed below chance.

A $6($ PROBE TYPE $) \times 5($ AGE GROUP $) \times 2($ GENDER $) \times 3($ SET $)$ repeated measures ANOVA shows a main effect for age group $[\mathrm{F}(4$; $86)=3.66, p<.01]$ and probe type $[\mathrm{F}(5 ; 430)=50.81, p<.001]$ and an interaction age group and probe type $[\mathrm{F}(20 ; 430)=3.65, p<.001]$. 
As suggested by graph 1, the adult group in the blood probe is the locus of the interaction - if the blood probe or the adult group is taken out of the analysis, the interaction vanishes. The one-way ANOVAs of age simple effects also point out that the main effect of age is a result of the interaction - age only makes a significant difference in the blood probe $[\mathrm{F}(4 ; 113)=11.76, p<.001]$. More specifically, Tukey post hoc tests of age simple sub-effects show that in the blood probe there are no significant differences among children age groups, and that all of them differ significantly from adults (all $p<.001$ ).

We also would like to point out an interesting pattern in the results, even if not statistically significant. Tukey post hoc tests of age main subeffects reveal that across probes adults diverge significantly from the 6 and 7 year olds $(p=.004$ and $p=.038$, respectively), but not from 4 and 5 year olds, who do not diverge significantly from 6 and 7 year olds (see graph 2). Granted the blood probe carries this difference: without the blood probe there is no age main effect, hence no age main sub-effects (see graph 3). Although the blood probe pulls down the overall performance of all children age groups more or less to the same extent, only the two older groups differ reliably from adults (compare graphs 3 and 2). This is because the blood probe adds to a previous difference existent in the first five probes: the curious pattern that 6 and 7 year olds, in particular 6 year olds, have a lower proportion of birth-parent answers than 4 and 5 year olds (see graph 3 and the first five probes of graph 1).

Finally, to measure the effect of the different types of probes, a 2 (KNOWN PROPERTIES vs. UNKNOWN PROPERTIES) $\times 2$ (BEHAVIOR vs. PHYSICAL TRAIT) $\times 5$ (AGE GROUP) $\times 2$ (GENDER) repeated measures ANOVA was run. The results show a main effect of familiarity $($ Known $=0.89$ and unknown $=0.80)[\mathrm{F}(1 ; 108)=16.91$, $p<.001$ ], and a main effect of type of property (physical trait $=0.87$ and behavior $=0.82)[\mathrm{F}(1 ; 108)=4.07, p=.046]$.

To sum up: (1) In the first four probes, across age groups, participants are more likely to choose a birth-parent answer for the known properties than for the unknown properties, and for the physical traits than for behaviors. (2) In the first five probes, all age groups perform significantly above chance, with no significant difference between them. (3) Also in the first five probes, there is the curious fact that in general 6 and 7 year olds 


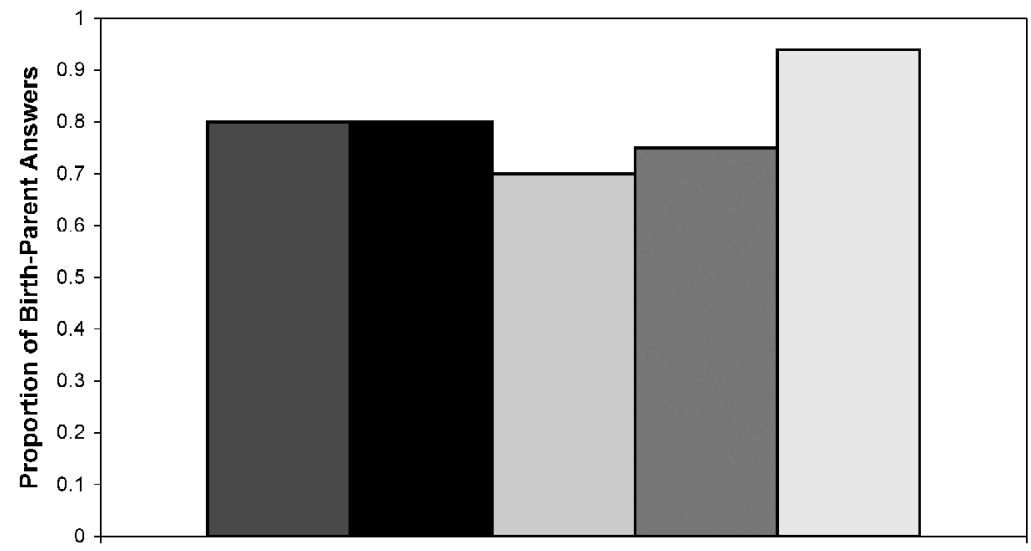

Probes Collapsed

Graph 2. Adoption Paradigm.

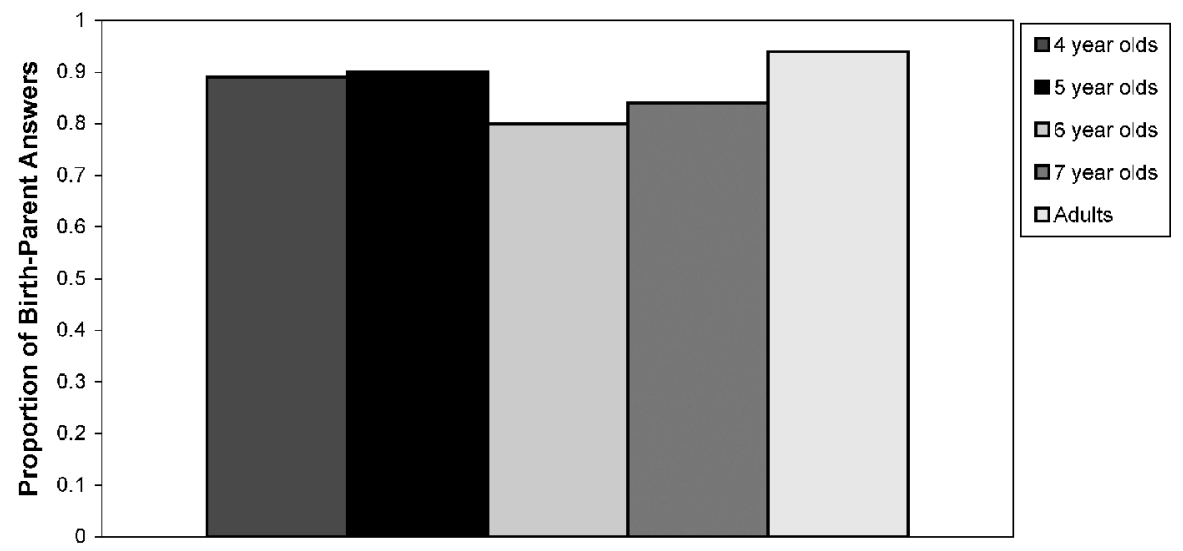

Probes Collapsed (except Blood)

Graph 3. Adoption Paradigm.

have a lower proportion of birth-parent answers than 4 and 5 year olds. (4) Finally, adults perform above chance in the blood probe; only half of the children age groups perform below chance, but all of them significantly different from adults. 


\section{Discussion}

We will argue that there is some relevant uniformity and continuity in the reasoning behind participants' birth-parent answers to the first five probes in the Brazilian data, one related to a notion of causal essentialism that seems to be entertained by participants in all ages. The one exception to strong discontinuity in the results, which concerns the blood kind probe, in fact seems to support our hypothesis.

The general structure of the reasoning implicit in all explanations is as follows:

(P1) Lineage assumption.

(P2) Permanence assumption.

(P3) Property assumption.

(C1) The grown-up baby is a $\mathrm{X}$ (from P1 \& P2).

(C2) The grown-up baby has A (from C1 \& P3).

(P1) assumes a relation of kind identity between kind $\mathrm{X}$ and its baby the baby of $\mathrm{X}$ is also a $\mathrm{X}$; (P2) assumes permanence under transformation - the baby $\mathrm{X}$ will be an adult $\mathrm{X}$; (P3) assumes that kind $\mathrm{X}$ has characteristic A.

Two remarks are important here. There was a simplification in our previous characterization of the hypotheses: we tried to maintain each one uniform, yet other explanatory combinations can be envisaged. For example, one could invoke a different hypothesis to explain a birthparent answer, by combining the property assumption (understood as a correlation) with the lineage and permanence assumptions (understood as natural kind laws). Actually, inasmuch as there are three types of assumptions (lineage, permanence, property), and each of them can be understood in three different ways (as a correlation, as a natural kind law, in essentialist terms), twenty-seven hypotheses could be characterized. In what follows, we shall consider this broader range of possibilities. However, we shall leave aside a pure combinatorial logic, and only keep track of the hypotheses that seem to show semantic coherence.

Furthermore, it is important to notice that there is a functional difference among the assumptions: $(\mathrm{P} 1)$ and $(\mathrm{P} 2)$ are knowledge that participants bring to the task, as it were; (P3) is an interpretation of 
a statement (and sometimes also of an image association) that is given by the probes of the task - e.g., "The cow's heart gets flatter when it sleeps and the pig's heart gets rounder when it sleeps" [drawings of the traits are shown — see Figure 3]. "Now that the baby is all grown up, when it sleeps does its heart get flatter like the one of the cow or get rounder like the one of the pig?" [drawings of the two parent animals are shown - see Figure 1]. This probe states that the cow has a flatter heart when it sleeps (and also associates the image of a cow with the image of a flat heart). In other words, while (P1) and (P2) are previous knowledge, (P3) is above all the specific interpretation that participants make of the property statement (or image association) given by the probe, the result of which being either a correlation, a natural kind law, or an essentialist understanding of the relation between kind $\mathrm{X}$ and characteristic $\mathrm{A}$.

With these remarks in mind, we assess which hypotheses may explain the birth-parent pattern of response in the first five research probes of the Brazilian data.

In the case of the kindhood probe, what is at stake is how participants conceive $(\mathrm{P} 1)$ and $(\mathrm{P} 2)$, since $(\mathrm{P} 1)$ and $(\mathrm{P} 2)$ are sufficient reasons to infer conclusion ( $\mathrm{C} 1)$, namely, that the grown-up baby is of the same kind of its birth parent. Since (P1) and (P2) are assumptions that are part of participants' previous knowledge, and we don't have any independent evidence on how participants represent (P1) and (P2), all hypotheses can equally explain the fact that in all age groups there is a significant birthparent pattern of response.

In the case of the property probes, what is at stake is participants' interpretation of the property statements (or image associations) given by the probes. It is this interpretation that constitutes $(\mathrm{P} 3)$; and $(\mathrm{P} 3)$ together with (C1) suffices to infer conclusion (C2), namely, that the grown-up baby has the characteristic A.

In the case of known property probes, all hypotheses can equally explain the fact that, in all age groups, there is a significant birthparent pattern of response. This is because: the property statements (or image associations) activate participants' previous knowledge; participants probably used this knowledge in their interpretation so as to assume (P3); and we have no independent evidence to decide how they entertain this previous knowledge. 
In the case of unknown property probes, matters are different. It seems unlikely that participant's interpretations of the property statements (or image associations) will result in a property assumption (P3) understood as a correlation or natural kind law. To result in a correlation, participant's interpretations would be driven by a domain general mechanism that computes empirical regularities. But considering that the statement (or an image association) asserts a novel relation, this type of mechanism would not form an assumption of regularity; hence, it would not form (P3) as a correlation. Yet without (P3), participants would be uncertain about projecting the unknown property to the grown-up baby; they wouldn't have a good reason to infer (C2). Concerning the natural kind law, there is a similar problem. Such understanding also depends on the computation of regularities, even if driven by a causal understanding of them. So, participants would not form (P3) as a natural kind law, and would be uncertain about projecting the unknown property to the grown-up baby. They also wouldn't have a good reason to infer (C2). ${ }^{15}$

Indeed, all explanatory combinations that have (P3) understood either as a correlation or as a natural kind law seem to suffer from the same problem. All hypotheses of this set of combinations would predict that participants do not form (P3), and therefore do not have a good reason to conclude (C2). Nonetheless, Brazilian participants performed significantly above chance in the unknown property probes. This implies that they had a good reason to infer $(\mathrm{C} 2)$, namely, that the grown-up baby has the unknown characteristic A. ${ }^{16}$

${ }^{15}$ The problem with Strevens' minimalism is that it is too minimal, implying a notion of causation that is too domain general. It is not that a more domain general notion of causation does not exist, or that it cannot be articulated with domain specific ones, but merely that it does not seem to have the projective power to explain this specific result. Strevens also phrases his natural kind laws as implying something more specific: "there is something about being a tiger that causes tigers to have stripes." But without any further specification of this something, it is not even possible to say that this natural kind law is a biological law. Actually, we suspect that, if he attempts such delimitation, his position will become a causal essentialism hypothesis. For a general discussion of Strevens' minimal hypothesis, see Ahn et al. 2001, Strevens 2000, 2001.

${ }^{16}$ This conclusion against this set of explanatory combinations requires a caution. It can be that the property statement of the task carries a notion of regularity, implying that the properties are characteristic, instead of arbitrary; if so, participants could have interpreted the statement as a correlation or a natural kind law. This is possible not only given the 
The notion of essence, even if used to understand causal regularities, has a theoretical role that is somewhat independent of the regularities, that is, it guides discovery of new regularities. Under uncertainty, participants can activate the notion of essence and use it as a template to understand unknown properties. If participants used a notion of essence to understand the novel relations presented by the probes, they could form (P3) and project unknown properties to the grown-up baby - i.e., they had a good reason to conclude (C2). Thus the hypothesis of an essentialist interpretation of the property statement does not provoke the problems that the other hypotheses seem to.

There are three interesting combinations that maintain an essentialist interpretation of the property assumption (P3). The first is the full causal essentialism hypothesis previously characterized, where a notion of essence is also used to understand $(\mathrm{P} 1)$ and $(\mathrm{P} 2)$. The second would drop the essentialist understanding of $(\mathrm{P} 1)$, holding it as a natural kind law, without the idea of essences being inherited. In this case, the notion of essence would be interpreted as responsible for the development and maintenance of characteristics and identity. The third would drop the essentialist understanding of both $(\mathrm{P} 1)$ and $(\mathrm{P} 2)$, holding them to be natural kind laws (or even correlations), without ideas of inheritance and innate potential. Here we would have a notion of causal essentialism as a general constraint on the categorization of all natural kinds, including cows and water, for example. Inasmuch as we lack independent evidence for how participants understand $(\mathrm{P} 1)$ and $(\mathrm{P} 2)$, all three hypotheses can equally explain the results of the unknown property probes.

The asymmetry between children and adults in the results of the blood probe seems to suggest that a full notion of causal essentialism was entertained by all participants, whereas the other hypotheses fail to

form of the property statement, but also due to the fact that, although the probes were randomized, some priming from the known property probes may be occurring. It's even possible that the property statement is taken as implying the logic-semantic properties of a universal statement, without any specific understanding in terms of correlation or natural kind law. This other possibility opens a new set of hypotheses as implicitly suggested by our independent characterization of the schematic versions of the lineage, permanence and property assumptions: participants may hold the assumptions in a strict logic-semantic sense, by interpreting similar linguistic versions from authoritative sources. This is not implausible, as far as young children are concerned. 
explain the asymmetry. If Brazilian children believe that blood transfusion changes kind identity because they identify essences with blood, as if blood were fulfilling the causal placeholder of essentialism, their adoptive-parent answers can be explained. Transfusion of the baby's blood implies that its essence was changed, and that the permanence assumption acquired a new status tied to the kindhood of the adoptive parent. Underscoring the plausibility of this explanation is the fact that in Brazil, as in many other places, adults talk about blood as if it were the substance that determines family kind identity: people are of the same family because they share the same blood. Even if this often seems to be a metaphorical or loose way of talk, ${ }^{17}$ Brazilian children may interpret this way of talk more literally, taking blood as the essence that determines family kind identity. In this case, they would have transposed this notion to understand the blood probe. This is likely insofar as the word 'baby' evokes the motherbaby relationship, and they may not have other conceptual resource to interpret the blood story. By contrast, adults didn't choose the adoptiveparent answers because they have already subscribed to a different notion of essence, one that probably identifies it with something in accordance with the scientific information they receive.

There seems to be two alternative explanations to this asymmetry in the blood probe. Perhaps what is behind children's answers is a notion of natural contagion by means of the contact with internal substances, a notion that adults don't take for granted. Indirect support for this speculation come from the fact that, when the pilot was run, we couldn't get a good result with the bias control probe when the question was phrased in terms of food. When we asked for justifications, children's answers seemed to imply a strong association between food and the identity of the mother, suggesting an association between milk as a contagious substance and the identity of the mother. ${ }^{18}$

${ }^{17}$ In Brazilian regions or social classes that are less influenced by the dissemination of scientific information, it does seem to imply a level of belief commitment, though.

${ }^{18} \mathrm{But}$ it is important to notice that this idea of natural contagion implying transmission of properties and identity is not necessarily incompatible with some notion of causal essentialism or some notion of biological mechanism. For example, some authors would interpret it as a case of a more general essentialist mode of construal (see Gelman \& Hirschfeld 1999), and others seem to interpret it as a different type of biological mechanism that does not involve essences (see Weissman \& Kalish 1999: 246). 
An alternative account might be that the asymmetry is simply an artifact of the task, a defect of our design: The last two research probes have exactly the same question ("now that the baby is all grown up, what kind of animal is it?"). If children do not have any belief about the relation between blood transfusion and species kind identity, the reiteration of the question in the context of the blood story may have driven them to infer the following implicature: the right answer should be different from my previous answer. This is because the additional information given by the blood story would make the second question irrelevant if the hearer cannot link the information to her previous beliefs, and suppose that the speaker was searching for the same answer. ${ }^{19}$ Accordingly, most children chose the adoptive-parent kind in the blood probe simply because most of them chose the birth-parent kind in the kindhood probe. Adult answers, by contrast, would be guided by the belief that blood transfusion does not change species-kind identity, the second probe achieving relevance as a test of the stability of this belief.

We don't think that this alternative account can fully explain children's answers in the blood probe. First, in other applications of the same design, we have no reliable asymmetry between results of the kind probe and those of the blood probe: the fact that children chose one answer in the kind probe does not predict a reversal in the blood probe (see Atran et al. 2001). Second, Brazilian children's justifications suggest that they weren't replying blindly. Many said: "it's because the blood of the baby was changed." Therefore, if there is a pragmatic bias in our design, it contributed to the results by interacting with other factors. For example, it may be that young children had a half understood idea of the relation between blood and essence, and the task suggested a relation of identity.

In short, we think that the data give some support to our hypothesis that Brazilian young children as well as adults used a full notion of causal essentialism to guide their performance, indicating that by ages 4 and 5 Brazilian children possess relevant folkbiological knowledge. The opposing view, which holds that only after age 7 do children start to have a folkbiological conception, requires a different interpretation. Although the underdetermination of hypotheses by evidence that came up often in our discussion pour oil on the opposing view's skepticism, the disaccord is more

\footnotetext{
${ }^{19}$ See Sperber \& Wilson 1995, for this pragmatic principle of relevance.
} 
radical: a different notion of what can count as evidence. In the opposing view, for a birth-parent type of answer to evince an early folkbiological conception, it has to be a component in a pattern of responses that differentiate physical and mental properties. In particular, young children have to project physical properties of the birth parent to the grown-up baby, and project belief properties of the adoptive parent to the grown-up baby, as adults do. Because our version of the adoption paradigm does not probe the projection of belief properties, it is not just that the birth-parent pattern of evidence we provide is insufficient; rather, any such pattern stemming from our set up would always be (see Astuti 2001, Bloch et al. 2001, Johnson \& Solomon 1997, Solomon et al. 1996). The opposing view also holds that, in any application of the property-differentiation paradigm to date, children up to age 7 do not differentiate in their pattern of projections. In brief, there is no available evidence that supports the view that younger children have a folkbiology.

Because there is a general incommensurability between our view and the opposing view concerning what is appropriate evidence, it is difficult to distinguish arguments of fact from arguments of meaning. To clarify the issue, consider the following:

Any epistemological claim concerning the suitability of evidence is theory-driven. The property-differentiation paradigm has a different criterion for what counts as evidence because it has a different conception of the nature of folkbiology. Actually, we think that this different conception is somewhat ambivalent, for there seems to be some equivocation in regard to the exact nature of the properties that should to be differentiated.

In more theoretical passages, what appears to be demanded is a general pattern of differentiation between body-property projections from the birth parent, and mind-property projections from the adoptive parent:

The overwhelming majority of Vezo adults drew a distinction between birth and nurture. They reasoned that birth is the mechanism responsible for the transmission of bodily traits, whereas nurture is the mechanism for the transmission of mental traits. Their inferences — That the adopted boy will resemble his birth parent in the shape of his ears, but will resemble his adoptive father in the belief about chameleons' teeth — were guided by a theory about the different character of the mind and body, and about the distinctive causal mechanisms affecting them. (Astuti 2001: 435, our emphases) 
Children's understanding of inheritance is a part of a larger framework of biological causal explanation only if birth is implicated in the origin of bodily features and not in the origin of beliefs and other properties that children know to be learned. Inheritance judgments must distinguish among properties in a manner that is consistent with the finding that preschool children know minds and bodies to be ontologically distinct. (Solomon et al. 1996: 152, our emphasis)

Here, the domain of folkbiology is tied to the body, in contraposition to the mind in general. It is as if the body and mind folk dualism were coextensive with the folk opposition between inheritance and learning.

In more methodological passages, what is prescribed is a more specific pattern of differentiation between physical-property projections from the birth parent, and belief-property projections from the adoptive parent:

The contrast of greatest theoretical interest is between the six physical traits (e.g., liver on the right/liver on the left) and the three beliefs (e.g., believes that skunks can see in the dark, believes that skunks cannot see in the dark), for a differentiation of these traits lies at the heart of the distinction between resemblance to family due to biological causes and that due to teaching and learning causes. The nine other traits were divided among three preferences (e.g. likes candy more than pickles/likes pickles more than candy), three skills (e.g., better at football than baseball/is better at baseball than football), and three temperaments (e.g. laughs all the time/is angry all the time). These traits were included mainly for exploratory reasons. (Solomon et al. 1996: 154)

Here, the conception of folkbiology is understood in terms of the contrast between physical properties that are inherited, and beliefs or other properties that are learned. This conception does not imply, as the previous does, that other mental properties - like preferences, temperaments and skills - fall outside the domain of folkbiology.

Our notion of causal essentialism is not necessarily related to either of these theoretical or methodological stances. Our notion concerns the explanation of the origin, development, and maintenance of the characteristics of living kinds, without implying anything about whether they are mental or body properties. In other words, the intuitions delivered by the notion of causal essentialism can crosscut the mind and body folk dualism. It is for this reason that the conflation between the body/mind and nature/nurture oppositions is misleading. These oppositions constitute rather two different 
dimensions of our biological intuitions: the notion of causal essentialism is fundamentally linked only to the latter; the former deals with the vital nature of the body in contraposition to the mind (and to matter, for that matter).

Furthermore, there is nothing intrinsic to the notion of causal essentialism that precludes it being applied to the content of beliefs. It is possible that young children initially apply the notion of causal essentialism indifferently to any type of property, and only later, when the notion is modulated by a larger biological framework (and also by a specific concept of learning), do they exclude beliefs. This later convergence to the adult conception that beliefs are not inherited may not be true of all cultures. If so, it would not be an appropriate standard for universally characterizing the domain of folkbiology. ${ }^{20}$ Even more important, this standard is vague, since the conception that beliefs are learned may depend on the type of content of the beliefs that one is probing.

Consequently, in our account, the evidence for causal essentialism is entirely independent from the property-differentiation criterion. The fact that children do not differentiate in the projection of belief properties and physical properties is not evidence against causal essentialism, only evidence against the existence of a "larger folkbiological framework." This larger framework is enriched by specific causal theories that can vary across cultures, such as vitalism in Japan (Hatano \& Inagaki 1999) and mechanism in the USA (Au \& Romo 1999).

The remainder of the dispute is chiefly definitional. Is it suitable to call the full notion of causal essentialism a 'folkbiology'? For us, this notion seems to constitute a specific set of intuitions regarding the properties of living kinds, including intuitions about internal structure, inheritance, relatedness, innate potential, and the development and maintenance of characteristics and identity. ${ }^{21}$

We conclude by highlighting another methodological problem, one that may be critical to the specific cross-species form of the propertydifferentiation paradigm. In the Brazilian results, we pointed out the fact that 6 and 7 year olds had a lower proportion of birth-parent answers

${ }^{20}$ But see Astuti 2001 and Bloch et al. 2001, for some evidence for a universal adult convergence.

${ }^{21}$ See Atran et al. 2001, where we discuss this definitional problem. 
than 4 and 5 year olds in the first five probes. Although this difference fails to reach statistical significance, we have some intriguing information that suggests another problem in interpreting results of the adoption paradigm. Some of the 6 and 7 year olds that had a strong pattern of adoptive-parent answers said that the story was similar to the movie Tarzan - a Walt Disney movie that has just this adoptive-parent bias. Actually, when one of us was explaining the design to the administrator of one of the schools where the experiment was run, she said explicitly that 4 and 5-year-olds would not get the right answer, but 6 and 7-year-olds would, because they had seen the movie Tarzan. ${ }^{22}$ Perhaps, then, the curious trend in the Brazilian data owes to the peculiar (though probably passing) influence of this highly captivating and idiosyncratic type of cultural instruction.

This leads to our final concern. Can we know the exact level of commitment that Tarzan kids had when they chose the adoptive-parent answer? Is it that they believe that the grown-up baby has the properties of the adoptive parents? Or is it that the story evoked an imaginary context that prompted their answers? Is it a stable belief fixed by Tarzan influence, or is it an ad hoc "fictional attitude" insinuated by an imaginary context? For now, we can only speculate. We think this kind of indeterminacy is a more general problem for paradigms like the adoption task that have stories that are susceptible of evoking imaginary contexts. If we don't know how literally young children apply the notion of beliefs to animals, then extending the property-differentiation paradigm to the cross-species case risks activating folkbiological imagination, instead of folkbiological knowledge.

\section{REFERENCES}

Ahn, W., Kalish, C., Gelman, S., Medin, D., Luhmann, C., Atran, S., Coley, J. \& Shafto, P.

2001 Why essences are essential in the psychology of concepts. Cognition 82: 59-69. ATRAN, S.

1987 Ordinary constraints on the semantics of living kinds: A commonsense alternative to recent treatments of natural-object terms. Mind and Language 2: 27-63.

${ }^{22}$ For her, the right answer was the adoptive-parent answer. She had such a constructivist mentality, that she couldn't even understand that being right or wrong was beside the point. 
1990 Cognitive foundations of natural history: Towards an anthropology of science. Cambridge, England: Cambridge University Press.

Atran, S., Medin, D., Lynch, E., Vapnarsky, V., UGan Ek', E. \& Sousa, P.

2001 Folkpsychology doesn't come from folkpsychology: Evidence from Yukatek Maya in cross-cultural perspective. Fournal of Cognition and Culture 1: 3-42.

AU, T. \& Romo, L.

1999 Mechanical causality in children's "folkbiology." In D. Medin \& S. Atran (Eds.), Folkbiology. Cambridge MA: MIT Press.

Astuti, R.

2001 Are we all natural dualists? A cognitive developmental approach. Fournal of the Royal Anthropological Institute 7: 429-447.

Bloch, M., Solomon, G. \& Garey, S.

2001 Zafimaniry: An undersanding of what is passed on from parents to children: A cross-cultural investigation. Fournal of Cognition and Culture 1: 43-68.

Garey, S.

1985 Conceptual change in childhood. Cambridge MA: MIT Press.

1995 On the origins of causal understanding. In D. Sperber, D. Premack \& A. Premack (Eds.), Causal Cognition. Oxford: Oxford University Press.

Carey, S. \& Spelke, E.

1994 Domain-specific knowledge and conceptual change. In L. Hirschfeld \& S. Gelman (Eds.), Mapping the mind: Domain specificity in cognition and culture. New York: Cambridge University Press.

Devitt, M. \& Sterelny, K.

1987 Language \& Reality. Great Britain: Basil Blackwell.

Gelman, S. \& Hirschfeld, L.

1999 How biological is essentialism? In D. Medin \& Atran (Eds.), Folkbiology. Cambridge, MA: MIT Press.

Gelman, S. \& Welman, H.

1991 Insides and essences. Cognition 38: 214-244.

Hatano, G. \& InAGAKi, K.

1994 Young children's naïve theory of biology. Cognition 50: 171-188.

1999 A developmental perspective on informal biology. In D. Medin \& S. Atran (Eds.), Folkbiology. Cambridge MA: MIT Press.

Johnson, S. \& CaRey, S.

1998 Knowledge enrichment and conceptual change in folkbiology: Evidence from people with Williams Syndrome. Cognitive Psychology 37: 156-200.

Johnson, S. \& Solomon, G.

1997 Why dogs have puppies and cats have kittens: The role of birth in young children's understanding of biological origins. Child Development 68: 404-419.

Kalish, C.W.

1995 Essentialism and graded membership in animal and artifact categories. Memory E Cognition 23: 335-353.

KeIL, F.

1989 Concepts, kinds, and cognitive development. Cambridge MA: MIT Press. 
MaMullin, E.

1978 Structural explanation. American Philosophical Quarterly 15: 139-147.

MEDin, D.

1989 Concepts and conceptual structure. American Psychologist 44: 1469-1481.

Medin, D. \& ORTONy, A.

1989 Psychological essentialism. In S. Vosniadou and A. Ortony (Eds.), Similarity and analogical reasoning. New York: Cambridge University Press.

Putnam, H.

1975 The meaning of 'meaning'. In Philosophical Papers, Vol. 2, Mind, Language and Reality. New York: Cambridge University Press.

Salmon, M., Earman, J., Glymour, C. \& Lennox, J.

1992 Introduction to the philosophy of science. Englewood Cliffs, NJ: Prentice Hall.

Solomon, G., Johnson, S., Zaitchik, D. \& Carey, S.

1996 Like father, like son: Young children's understanding of how and why offspring resemble their parents. Child Development 67: 151-171.

SPERBER, D. \& Wilson, D.

1995 Relevance: communication and cognition. Basil Blackwell.

SPRINGER, K.

1995 Acquiring a naïve theory of kinship through inference. Child Development 66: 547-558.

1996 Young children's understanding of a biological basis for parent-offspring relations. Child Development 67: 2841-2856.

Strevens, M.

2000 The essentialist aspect of naïve theories. Cognition 74: 149-175.

2001 Only causation matters: reply to Ahn et al. Cognition 82: 71-76.

Weissaman, M. \& Kalish, C.

1999 The inheritance of desired characteristics: Children's view of the role of intention in parent-offspring Resemblance. Fournal of Experimental Child Psychology 73: 245265. 


\section{Appendix}

\section{Known Properties}

Physical trait

Behavior

Physical trait

Behavior

Physical trait

Behavior

\section{Unknown Properties}

Physical trait

Behavior

Physical trait

Behavior

Physical trait

Behavior
TURTLE

shell on its back

walks slowly

PIGEON

short neck

very used to flying

high

COW

straight tail

moo
TOAD

warts on its back

hops

GOOSE

long neck

very used to lie on

the water

PIG

curly tail

oink

\section{TURTLE/TOAD}

stomach gets harder

when it sleeps

opens its eyes when

afraid

stomach gets softer

when it sleeps

closes its eyes when

afraid

PIGEON/GOOSE

blood become thick

blood become thin and and Sticky when it sleeps

stops when it sees

a Banana tree

stops when it sees

a orange tree

\section{$\mathrm{COW} / \mathrm{PIG}$}

heart gets flatter

when it sleeps

heart becomes rounder

when it sleeps

runs after ducks 